Journal of Agricultural Sciences
(Tarim Bilimleri Dergisi)

\title{
Application of Different Drying Techniques on Peach Puree
}

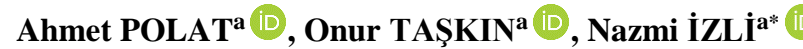

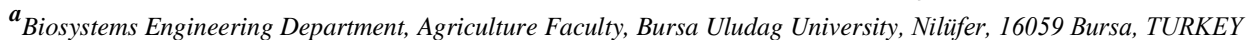 \\ ARTICLE INFO \\ Research Article \\ Corresponding Author: Nazmi IZLİ, E-mail: nazmiizli@gmail.com \\ Received: 23 July 2019 / Revised: 05 February 2020 / Accepted: 21 February 2020 / Online: 31 May 2021
}

ABSTRACT

In this study, six various applications were performed to dry peach puree using methods of convective drying (CD), microwave drying (MW1, MW2 and MW3) and combined convective-pulsed microwave drying (CD+MW2 and $\mathrm{CD}+\mathrm{MW} 3)$. Effect of drying on time, color, $\mathrm{pH}$, Brix and micrographs were evaluated. The data of total drying time revealed that the maximum value was belonged to "CD" (220 min). The minimum value was obtained by "MW1" (10 min). By comparison of total color change $(\Delta E)$, the highest values were achieved with "CD+MW3", whereas the lowest values were achieved with "MW2". Under all drying applications, the maximum $\mathrm{pH}$ and Brix changes were observed with "CD+MW2". From the microstructure, the samples to which the microwave method was applied displayed a collapsed structure as to the sample dried by the convective method.

Keywords: Drying time, pH, Brix, Color, SEM

(C) Ankara University, Faculty of Agriculture

\section{Introduction}

Peach (Prunus persica L.) parts of the family of Rosaceae (Liu et al. 2017) and is now cultivated widely in subtropical regions of the World (Zhang et al. 2017). Total worldwide production was approximately 22.8 million tons in 2014 (FAO 2017). However, high moisture content causes rapid perishability (Zhu \& Shen 2014), so peaches should be eaten as fresh throughout the year (Golisz et al. 2013) or be preserved in some form (Kingsly et al. 2007) for instance by using drying methodologies to extend their shelf life (Lyu et al. 2017). Usually, dried peaches are used in bakery, cake, fruit leather and sauces (Doymaz 2014). Peach fruit is also a source of vitamins, minerals and beneficial plant compounds (Doymaz \& Bilici 2014) and a helpful ingredient of the diet (Fuentes-Pérez et al. 2014).

The drying process associates simultaneous coupled heat-mass transfer (Cui et al. 2004). Meanwhile, the drying process has a significant influence on the sensory and nutritional characteristics of the end-product (Lyu et al. 2017). Hence to obtain a consistent quality dried product, various dryers should be utilized (Golisz et al. 2013). Drying technologies such as far-infrared and microwave (Wang \& Sheng 2006), hot air (Doymaz \& Bilici 2014), convection (Zhu \& Shen 2014), short and medium infrared under vacuum (Chayjan \& Allai 2016), freezing (Pieniazek \& Messina 2017), infrared with explosion puffing (Lyu et al. 2017) and osmotic pretreated infrared (Zhang et al. 2017) have been applied to peaches. Due to the dense physical structure and chemical composition factors, sliced fruits dry quite slowly and considerable darkening occurs during drying (Sankat \& Castaigne 2004). In view of the drying method problem mentioned above, the puree drying process is a comparably inexpensive and simple process that requires shorter drying periods and lower drying temperatures (Karim \& Wai 1999). For the food industry, peach purees are substantial and used as ingredients in many products such as juices, beverages, jellies, jams and baby foods (Massa et al. 2010).

In this research, the main objective was to compare the effect of convective, microwave and combined convective-pulsed microwave drying applications on peach puree, and to provide an alternative puree drying application for industrial purposes considering to drying curves, color, $\mathrm{pH}$, Brix and microstructure.

\section{Material and Methods}

\subsection{Drying experiments}

Fresh samples of peaches were bought from the local market in the Bursa province of Turkey. The samples stored in a refrigerator at a temperature of $+4 \pm 0.5^{\circ} \mathrm{C}$ to reduce chemical and physiological changes and prevent moisture loss. In experiments, healthy 
and matured fruit samples were used. Initial moisture content were specified by keeping the samples in an oven dryer (M3025P, Electromag, Turkey) at $105^{\circ} \mathrm{C}$ for $24 \mathrm{~h}$ (Celen \& Kahveci 2013). The moisture content of fruits was determined $4.73 \mathrm{~g}$ water.g dry matter ${ }^{-1}$.

Drying applications were done in a custom-modified pulsed microwave-convective dryer with each $60 \mathrm{~g}$ peach purees. The experimental conditions of drying included the following: convective drying of $60^{\circ} \mathrm{C}(\mathrm{CD})$, microwave drying at $200 \mathrm{~W}$ (MW1), microwave drying at $200 \mathrm{~W}$ in pulse ratio of 2 (MW2) and 1.5 (MW3), and combined convective-pulsed microwave drying. The pulse ratio $(P R)$ for each run was computed as $P R=\left(t_{\text {on }}+t_{\text {off }}\right) / t_{\text {on }}$. Here, $t_{\text {on }}$ is the "on" time of magnetron power and $t_{\text {off }}$ is the "off" time of magnetron power (Gunasekaran \& Yang 2007). During the study, the 30s of $\mathrm{t}_{\text {on }}$ and 30 s of $\mathrm{t}_{\text {off }}$ represented PR=2, and 40s of $\mathrm{t}_{\mathrm{on}}$ and $20 \mathrm{~s}$ of $\mathrm{t}_{\mathrm{off}}$ represented $\mathrm{PR}=1.5$. A digital balance (Radwag, Poland) was used for the determination of sample weights that were saved at 5 min intervals (Kumar \& Shrivastava 2017).

\subsection{Drying curves}

The Equation 1 and 2 were applied to calculate the $M R$ (moisture ratio) and $D R$ (drying rate) at the time of drying experiments (Thorat et al. 2012):

$$
\begin{aligned}
& M R=\frac{M_{t}-M_{e}}{M_{0}-M_{e}} \\
& D R=\frac{M_{t+d t}-M_{t}}{d t}
\end{aligned}
$$

Where, $M_{t}, M_{o}$, and $M_{e}$ refer to the moisture content at a given time, the initial moisture content and the equilibrium moisture content, respectively. $M_{t+d t}$ is the moisture content at $t+d t$ and $t$ is the drying time (min). After analyzing the formula, the values $M_{e}$ are rather small concerning $M_{t}$ or $M_{o}$. Ultimately as proposed by some of the researchers, the moisture ratio formula was shortened as follows:

$$
M R=\frac{M_{t}}{M_{o}}
$$

\subsection{Color analysis}

A Hunterlab Color Analyzer (MSEZ-4500L, Reston, USA) was used to determine the color attributes of fresh (as the reference value) and dried peach samples regarding to the lightness $\mathrm{L}^{*}$ (white [100] - black [0]) and $\mathrm{a}^{*}$ (red [+] - green [-]) and $\mathrm{b}^{*}(\mathrm{yellow}$ [+] - blue [-]). The $C$ (Chroma), $\alpha^{\circ}$ (Hue angle) and $\Delta E$ (total color difference) values were determined according to Eq. (4-6) given below where $L_{0}, a_{0}$, and $b_{0}$ represent the reference value (Purkayastha et al. 2013).

$$
\begin{aligned}
& C=\sqrt{\left(a^{2}+b^{2}\right)} \\
& \alpha=\tan ^{-1}\left(\frac{b}{a}\right) \\
& \Delta E=\sqrt{\left(L_{0}-L\right)^{2}+\left(a_{0}-a\right)^{2}+\left(b_{0}-b\right)^{2}}
\end{aligned}
$$

\section{4. $p H$ and Brix determination}

For peach samples, a pH meter (6173, Jenco, USA) was used to determine the $\mathrm{pH}$ values at room temperature. Before the measurements, two-point buffers at $\mathrm{pH}=7.0$ and 4.0 were applied to calibrate. On the other hand, a digital refractometer (MA871, Milwaukee, Romania) was used to measure the level of sugar, Brix (Mechlouch et al. 2012).

\subsection{Microstructure evaluation}

The influence of various drying applications on the microstructures of peach samples was examined by using SEM (EVO 40, Carl Zeiss, Oberkochen, Germany). Particles were extracted from the dried samples and these was coated with gold-palladium. Microphotographs were taken and considered under a high vacuum (20 kV) (SCD-005, Baltec, Wetzlar, Germany) (Tian et al. 2015). 


\subsection{Statistical analysis}

Randomized plots factorial design of experimental type was performed during the study. Triplicate runs were done in experiments. The JMP software (Version 7.0; SAS Institute Inc., USA) was used for the analysis of variance (ANOVA). To compare the mean values at the 5\% significance level $(\mathrm{P}<0.05)$, the LSD (least significant difference) test was applied.

\section{Results and Discussion}

\subsection{Drying curves}

The impacts of different drying applications (CD, MW1, MW2, MW3, CD+MW2 and CD+MW3) on the moisture content versus drying time and drying rate in drying period of peach purees are demonstrated in Figure 1 and 2, respectively. As shown, it took 220, 10, 105, 15, 40 and 20 min to reach the final moisture content at "CD", "MW1", "MW2", "MW3", "CD+MW2" and "CD+MW3", respectively. The results express that increasing microwave power "on" time, the drying times of peach purees decreased. Based on the previous peach drying studies, the required drying time reaching the final moisture content was found for air temperatures of $45^{\circ} \mathrm{C}(765 \mathrm{~min}), 55^{\circ} \mathrm{C}(500 \mathrm{~min}), 65^{\circ} \mathrm{C}(310)$ and $75^{\circ} \mathrm{C}(225 \mathrm{~min})$ (Doymaz \& Bilici 2014). Also, the various infrared power levels were needed $400 \mathrm{~min}$ (83 W), $240 \mathrm{~min}$ (125), $130 \mathrm{~min}$ (167) and $90 \mathrm{~min}$ (209 W) (Doymaz 2014). Additionally, Eştürk \& Soysal (2010) and Soysal et al. (2009) have reported an observation parallel to our study on the effect of microwave with continuous and intermittent microwave-convective drying of dill and oregano, respectively. Depending on both researches, the continuous treatments led to shorter drying times. In the present study, "CD" resulted in the longest drying time, whereas a significant reduction in drying time was observed when "CD+MW2" and "CD+MW3" combinations were used. These results are in relevance with the research of Soysal et al. (2009) on red pepper drying. The duration for the convective drying applications was found approximately 10.4-19.6 and 2.5-11.8 times longer than that in the continuous microwave-convective method and intermittent microwave-convective method depending on the microwave output power and PR, respectively. Similarly, Eştürk (2012) studied the drying of sage leaves with intermittent and continuous microwave-convective drying methods and the drying time of the convective drying was determined to be 64 to 112 times longer than that of the PR=1.

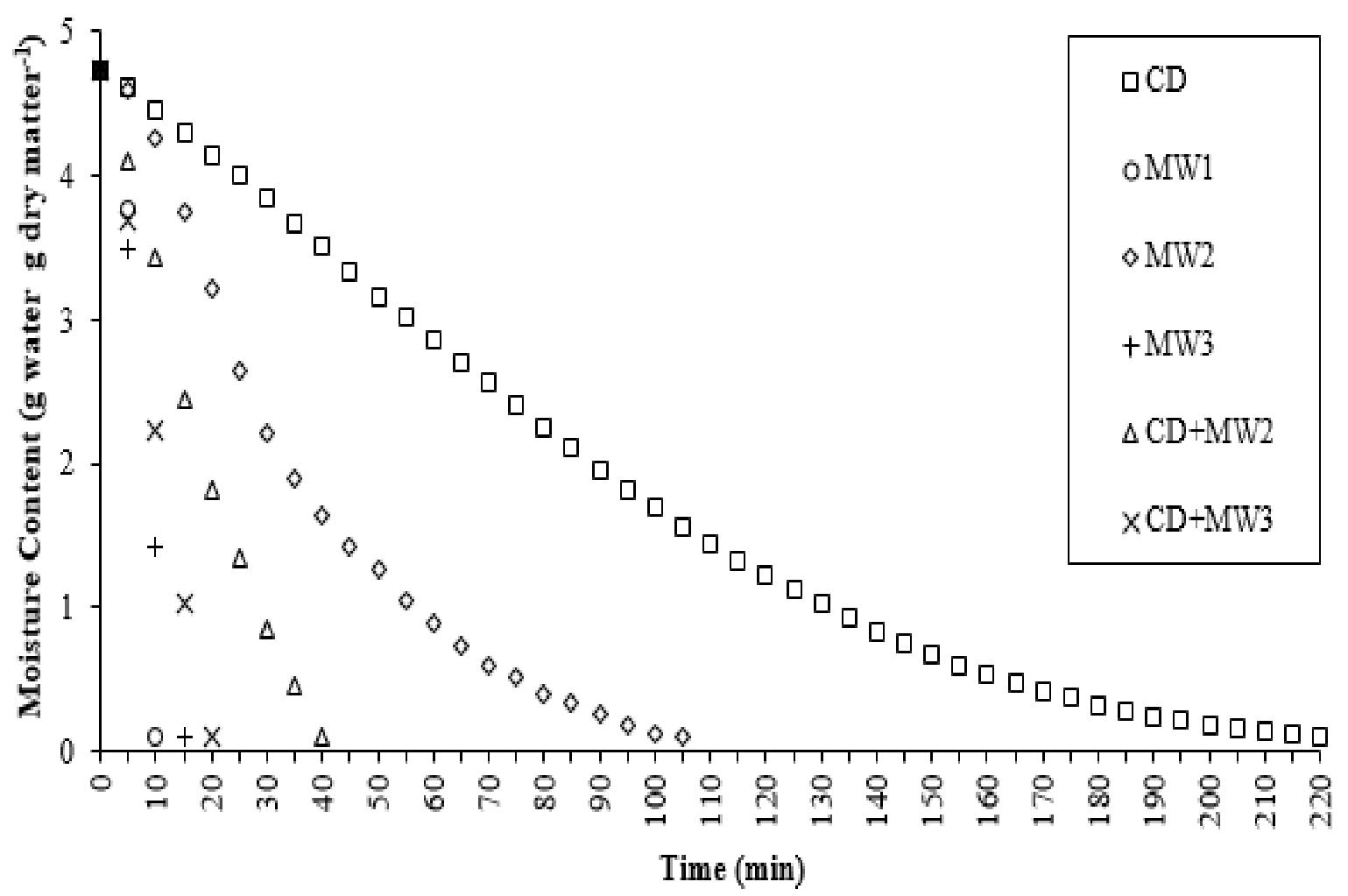

Figure 1- The moisture content vs. time of peach puree at drying applications 


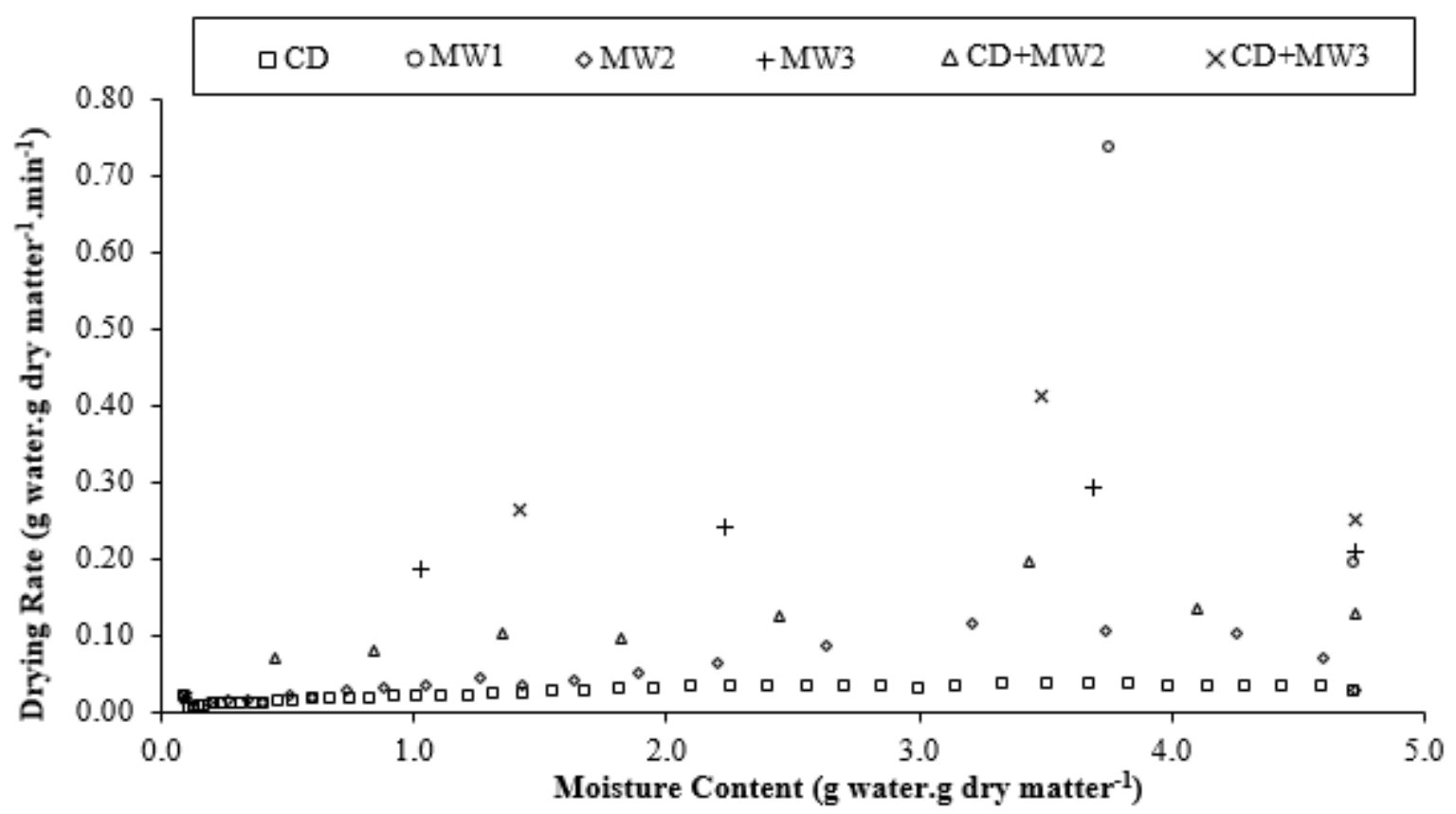

Figure 2- The drying rate vs. moisture content of peach puree at drying applications

\subsection{Color analyses}

The color changes of the different drying applications are displayed in Figure 3 . The parameters of $L_{0}, a_{0}$, and $b_{0}$ of peach puree were $69.72,14.43$, and 63.50, respectively. Compared to the fresh sample, drying with "MW2" generated the highest $L$ value (58.27) and the lowest $\Delta E$ value (13.53). Additionally, any other drying applications in the present study had significantly $(\mathrm{P}<0.05)$ higher values than the fresh peach puree sample. Of all the drying applications, the $b$ value was notably $(\mathrm{P}<0.05)$ at the highest for the dried sample with "CD+MW2" $(60.35)$. Besides, the lowest values of $C$ were found to be similar for peach purees dried either using the "CD" or the "CD+MW3" application $(\mathrm{P}<0.05)$. There were statistically significant differences between $\alpha$ values of all drying applications $(\mathrm{P}<0.05)$. Contrary to our study, Pieniazek \& Messina (2017) presented different color values $(L, a$, and $b)$ in both fresh $(85.03,1.02$ and 43.11) and freeze-dried $(80.33,0.91$ and 40.02) peach samples. Although freezedrying is recognized with its characteristic to provide high-quality final products (Khampakool et al. 2019), the differences between fresh samples can be explained with the growth conditions, genetic factors and harvesting times (Er \& Özcan 2010). Furthermore, Contreras et al. (2008) investigated the microwave method on convective drying for the color parameters of apple and strawberry. The application of higher microwave or air temperature has impacted in lesser color difference in the samples of dried apple. Besides, microwaves had a positive effect on sample lightness (higher $L$ values), which could lead to the discoloration at surface level in line with the higher temperature reached at the time of drying for dried strawberry samples. Likewise, Junqueira et al. (2017) studied the microwave, convective, and intermittent microwave-convective methods effect on pumpkin (Cucurbita moschata Duch.) slices drying. Lower values of $a$ were found after the convective drying process, indicating that losses of red coloration and microwave treatments were suggesting better color quality.

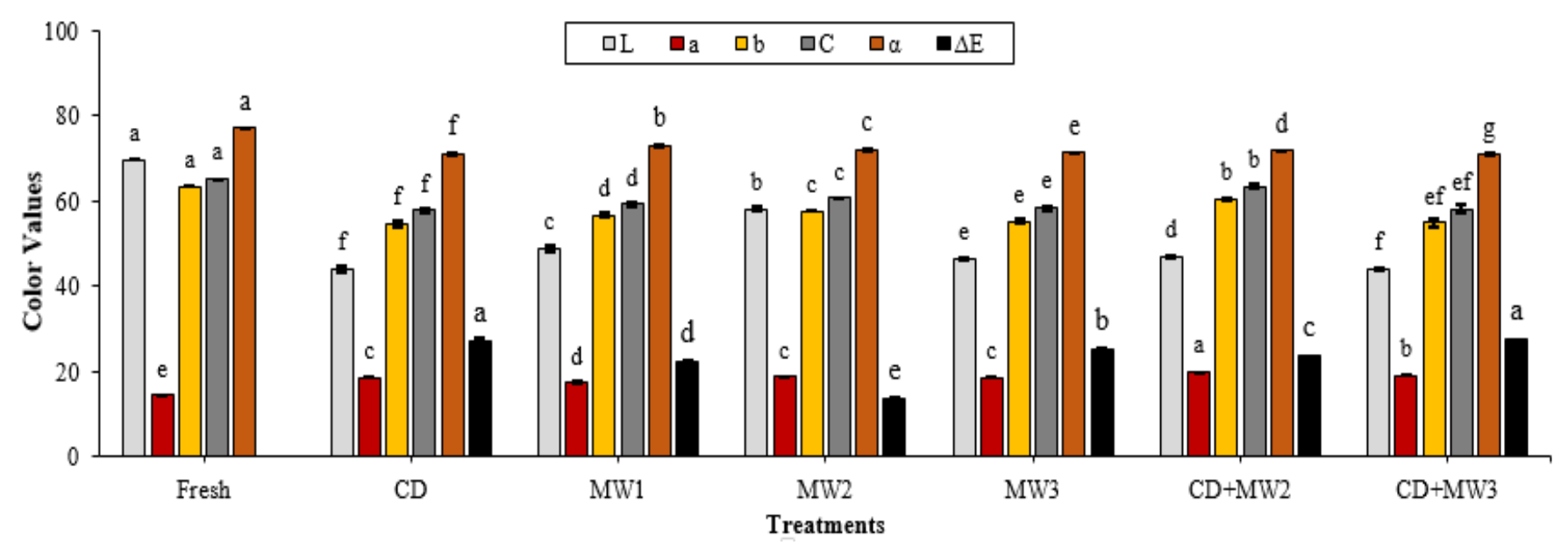

Figure 3- Color changes of peach puree at drying applications 


\section{3. $\mathrm{pH}$ and Brix analyses}

Figure 4 shows the $\mathrm{pH}$ and Brix values for the dried and fresh samples of peach puree. The results gathered from the pH analysis showed that all drying applications increased the $\mathrm{pH}$ content from 4.26 (fresh) to 4.41 (CD+MW2). Although the drying process affected the $\mathrm{pH}$ variation, there were no differences in $\mathrm{pH}$ values between "CD" and "MW3". Furthermore, the Brix content in the fresh peach puree was 9.00. The changes in Brix values were increased with all drying experiments. Among the six drying experiments, the highest Brix value (78.00) was recorded with "CD+MW2", while the lowest values (40.80) were recorded with “CD”. Results of our study were similar by Fuentes-Pérez et al. (2014). The pH and Brix values of six peach cultivars (O'Henry, Ryan Sun, Summer Rich, Ruby Rich, Spring Lady and Royal Glory) were measured between 3.40-4.12 and 7.93-14.08, respectively. Also, Mechlouch et al. (2012) investigated the tomato drying with microwave drying with three output powers density $\left(1,2\right.$ and $\left.3 \mathrm{~W} \mathrm{~g}^{-1}\right)$ at two temperatures $\left(57\right.$ and $\left.67^{\circ} \mathrm{C}\right)$. The $\mathrm{pH}$ - Brix values for tomato dried in microwave power of 1 , 2 and $3 \mathrm{~W} \mathrm{~g}^{-1}$ at a constant drying air temperature $\left(57^{\circ} \mathrm{C}\right)$ were $4.86-1.50,4.50-2.00$ and $4.29-5.13$, respectively. At a constant $67{ }^{\circ} \mathrm{C}$ drying air temperature, the $\mathrm{pH}$ - Brix values were $4.91-1.00,4.53-1.88$ and $4.42-3.00$ at a microwave power of 1,2 and $3 \mathrm{~W} \mathrm{~g}^{-1}$, respectively. Zade \& Lakade (2017) applied microwave heating and convective hot air drying to produce raisins from grapes with desirable quality aspects. Experiments were performed by changing two process parameters of hot air temperature and specific microwave power density in the range of 35 to $55^{\circ} \mathrm{C}$ and 0.15 to $0.35 \mathrm{~W} \mathrm{~g}^{-1}$, respectively. The optimal combination at $45^{\circ} \mathrm{C}$ hot air temperature and $0.25 \mathrm{~W} \mathrm{~g}^{-1}$ specific microwave power density resulted in the $4.03 \mathrm{pH}$ and 77.19 Brix values.

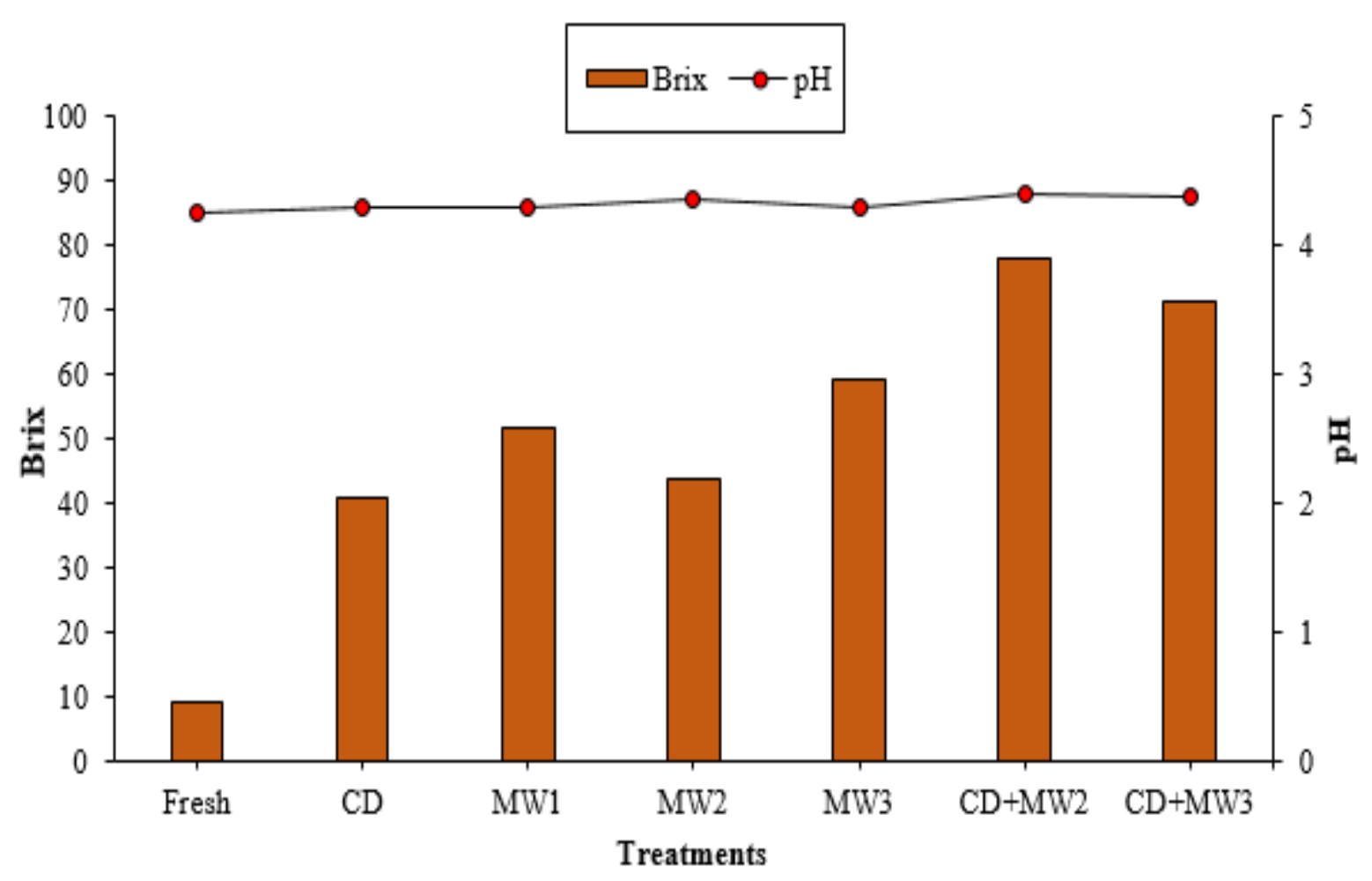

Figure 4- pH and Brix Comparison of peach puree at drying applications

\subsection{Microstructure analyses}

The impact of different drying applications on the tissue structure of the dried peach puree was determined by using SEM (scanning electron microscopy) (Figure 5a-f). The micrographs were examined through $2000 \times$ microscopy. The "CD" dried samples were demonstrated to be distribution that is more regular. Other applications caused the fissure structure. However, the highest distortion was seen in the "MW1" treatment. Lyu et al. (2017) imaged peach samples as well. Although a uniform porous structure was shown in fresh peach samples, the loose structure with the highest sugar penetration existed after infrared drying. Similarly, Witrowa-Rajchert \& Rzaca (2009) determined the influence of drying on the internal structure of dried apples. The results present that regarding the structural properties, the apples dried by the convective method are significantly different (small cavities and very high density) from convective-microwave dried apples. In addition, Izli \& Isik (2015) researched the microwave, convective and microwave-convective methods for the microstructure characteristics of tomatoes. Although after convective drying at 50 and $75{ }^{\circ} \mathrm{C}$ microstructure was detectable, the microwave-convective drying conditions caused structural damages by destroying the external surfaces of the samples. 

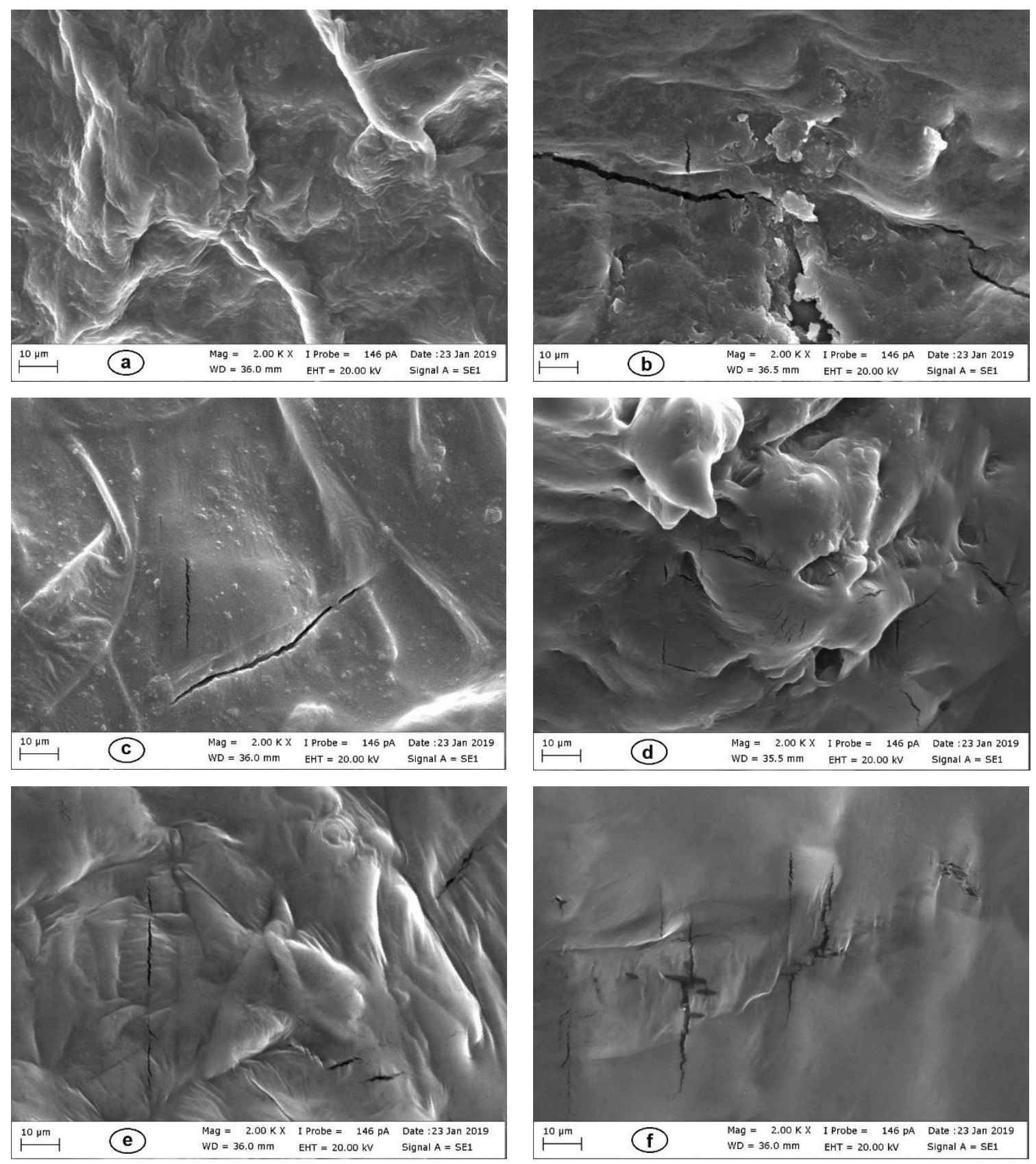

Figure 5- Microstructure of peach puree: CD (a), MW1 (b), MW2 (c), MW3 (d), CD+MW2 (e) and CD+MW3 (f)

\section{Conclusions}

In the presented study, drying curves, color, $\mathrm{pH}$, Brix and microstructure of peach puree were analyzed by performing convective, microwave, pulsed microwave and pulsed microwave-convective drying. According to the experimental results, the "MW1" drying condition showed the shortest drying time and minimum $\mathrm{pH}$ change. Comparing the color values, all applications had a negative effect on the color values except $a$ value. Moreover, total color differences $(\Delta E)$ were found lowest with "MW2". However, the scanning electron micrographs showed that microwave applications disrupted the clear and porous structure. As a conclusion of drying time and drying rate comparisons, it was found that microwave usage had a favorable effect on the drying of peach puree. Furthermore, some quality analysis was also showed that the "CD+MW2" has considerably higher values over the other drying methods in terms of $\mathrm{pH}$, Brix and $a, b$ and $C$ color values.

\section{Acknowledgments}

The authors grateful to the Bursa Uludag University Research Foundation Unit for their financial support of Project No. OUAP(Z)-2017/1. 


\begin{tabular}{|ll|}
\hline Abbreviations and Symbols \\
\hline$C D$ & Convective drying \\
$d b$ & dry basis \\
$M_{0}$ & Initial moisture content, g water.g dry matter ${ }^{-1}$ \\
$M_{t}$ & The moisture content at a particular time, g water.g dry matter \\
$M_{e}$ & Equilibrium moisture content, g water.g dry matter" \\
$M R$ & Moisture ratio \\
$M W$ & Microwave drying \\
$P R$ & Pulse ratio \\
$S E M$ & Scanning electron microscopy \\
$t_{o n}$ & Magnetron power "on" time \\
$t_{\text {off }}$ & Magnetron power "off" time \\
\hline
\end{tabular}

\section{References}

Celen S \& Kahveci K (2013). Microwave drying behaviour of tomato slices. Czech Journal of Food Science 31(2): 132-138 https://doi.org/10.17221/30/2012-CJFS

Chayjan A R \& Allai B (2016). Comparison of short and medium infrared radiation on drying parameters of peach slices under vacuum conditions. Food Science and Technology 13(58): 107-116

Contreras C, Martín-Esparza M E, Chiralt A \& Martínez-Navarrete N (2008). Influence of microwave application on convective drying: Effects on drying kinetics, and optical and mechanical properties of apple and strawberry. Journal of Food Engineering 88(1): 55-64 https://doi.org/10.1016/j.jfoodeng.2008.01.014

Cui Z W, Xu S Y \& Sun D W (2004). Microwave-vacuum drying kinetics of carrot slices. Journal of Food Engineering 65(2): 157-164 https://doi.org/10.1016/j.jfoodeng.2004.01.008

Doymaz I (2014). Suitability of thin-layer drying models for infrared drying of peach slices. Journal of Food Processing and Preservation 38(6): 2232-2239 https://doi.org/10.1111/jfpp.12277

Doymaz İ \& Bilici B (2014). Influence of citric acid pretreatment on drying of peach slices. International Journal of Food Engineering 10(4): 829-837 https://doi.org/10.1515/ijfe-2014-0026

Er F \& Özcan M M (2010). Chemical compositional properties and mineral contents of some apple cultivars. South-Western Journal of Horticulture Biology and Environment 1(2):121-131

Eştürk O (2012). Intermittent and continuous microwave-convective air-drying characteristics of sage (Salvia officinalis) leaves. Food and Bioprocess Technology 5(5): 1664-1673 https://doi.org/10.1007/s11947-010-0462-x

Eştürk O \& Soysal Y (2010). Drying properties and quality parameters of dill dried with intermittent and continuous microwave-convective air treatments. Journal of Agricultural Sciences 16(1): 26-36

FAO (2017). Food and Agricultural Organization Statistica Database. Retrieved in April, 01,2019 from http://faostat3.fao.org/download/Q/QC/E

Fuentes-Pérez M C, Nogales-Delgado S, Ayuso M C \& Bohoyo-Gil D (2014). Different peach cultivars and their suitability for minimal processing. Czech Journal of Food Sciences 32(5): 413-421

Golisz E, Jaros M \& Kalicka M (2013). Analysis of convectional drying process of peach. Technical Sciences 16(4): 333-343

Gunasekaran S \& Yang H W (2007). Effect of experimental parameters on temperature distribution during continuous and pulsed microwave heating. Journal of Food Engineering 78(4): 1452-1456 https://doi.org/10.1016/j.jfoodeng.2006.01.017

Junqueira J R D J, Corrêa J L G \& Ernesto D B (2017). Microwave, convective, and intermittent microwave-convective drying of pulsed vacuum osmodehydrated pumpkin slices. Journal of Food Processing and Preservation 41(6): e13250 https://doi.org/10.1111/jfpp.13250

Izli N \& Isik E (2015). Color and microstructure properties of tomatoes dried by microwave, convective, and microwave-convective methods. International Journal of Food Properties 18(2): 241-249 https://doi.org/10.1080/10942912.2013.829492

Karim A A \& Wai C C (1999). Foam-mat drying of starfruit (Averrhoa carambola L.) puree. Stability and air drying characteristics. Food Chemistry 64(3): 337-343 https://doi.org/10.1016/S0308-8146(98)00119-8

Khampakool A, Soisungwan S \& Park S H (2019). Potential application of infrared assisted freeze drying (IRAFD) 242 for banana snacks: Drying kinetics, energy consumption, and texture. LWT - Food Science and Technology 99: 355-363 https://doi.org/10.1016/j.lwt.2018.09.081

Kingsly R P, Goyal R K, Manikantan M R \& Ilyas S M (2007). Effects of pretreatments and drying air temperature on drying behaviour of peach slice. International Journal of Food Science \& Technology 42(1): 65-69 https://doi.org/10.1111/j.1365-2621.2006.01210.x

Kumar V \& Shrivastava S L (2017). Optimization of vacuum-assisted microwave drying parameters of green bell pepper using response surface methodology. Journal of Food Measurement and Characterization 11(4): 1761-1772 https://doi.org/10.1007/s11694-017-9557-7

Liu C J, Wang H O, Xue Y L, Zhang Z Y, Niu L Y, Li D J \& Liu C Q (2017). Screening quality evaluation factors of freeze-dried peach (Prunus Persica L. Batsch) powders from different ripening time cultivars. Journal of Food Quality pp. 1-12 https://doi.org/10.1155/2017/7213694

Lyu J, Yi J, Bi J, Chen Q, Zhou L \& Liu X (2017). Effect of sucrose concentration of osmotic dehydration pretreatment on drying characteristics and texture of peach chips dried by infrared drying coupled with explosion puffing drying. Drying Technology 35(15): 1887-1896 https://doi.org/10.1080/07373937.2017.1286670.

Massa A, González C, Maestro A, Labanda J \& Ibarz A (2010). Rheological characterization of peach purees. Journal of Texture Studies 41(4): 532-548 https://doi.org/10.1111/j.1745-4603.2010.00240.x

Mechlouch R F, Elfalleh W, Ziadi M, Hannachi H, Chwikhi M, Aoun A B \& Cheour F (2012). Effect of different drying methods on the physico-chemical properties of tomato variety 'Rio Grande'. International Journal of Food Engineering 8(2): 1-13 https://doi.org/10.1515/1556-3758.2678 
Pieniazek F \& Messina V (2017). Quality parameters of freeze-dried peach snack. British Food Journal 119(12): 2959-2968 https://doi.org/10.1108/BFJ-11-2016-0526

Purkayastha M D, Nath A, Deka B C \& Mahanta C L (2013). Thin layer drying of tomato slices. Journal of Food Science and Technology 50(4): 642-653 https://doi.org/10.1007/s13197-011-0397-x

Sankat C K \& Castaigne F (2004). Foaming and drying behaviour of ripe bananas. LWT-Food Science and Technology 37(5): 517-525 https://doi.org/10.1016/S0023-6438(03)00132-4

Soysal Y, Arslan M \& Keskin M (2009). Intermittent microwave-convective air drying of oregano. Food Science and Technology International 15(4): 397-406 https://doi.org/10.1177/1082013209346588

Soysal Y, Ayhan Z, Eştürk O \& Arıkan M F (2009). Intermittent microwave-convective drying of red pepper: Drying kinetics, physical (colour and texture) and sensory quality. Biosystems Engineering 103(4): 455-463 https://doi.org/10.1016/j.biosystemseng.2009.05.010

Thorat I. D, Mohapatra D, Sutar R F, Kapdi S S \& Jagtap D D (2012). Mathematical modeling and experimental study on thin-layer vacuum drying of ginger (Zingiber officinale R.) slices. Food and Bioprocess Technology 5(4): 1379-1383 https://doi.org/10.1007/s11947-0100429-y

Tian Y, Wu S, Zhao Y, Zhang Q, Huang J \& Zheng B (2015). Drying characteristics and processing parameters for microwave-vacuum drying of kiwifruit (Actinidia deliciosa) slices. Journal of Food Processing and Preservation 39(6): 2620-2629 https://doi.org/10.1111/jfpp.12512

Wang J \& Sheng K (2006). Far-infrared and microwave drying of peach. LWT-Food Science and Technology 39(3): 247-255 https://doi.org/10.1016/j.lwt.2005.02.001

Witrowa-Rajchert D \& Rząca M (2009). Effect of drying method on the microstructure and physical properties of dried apples. Drying Technology 27(7-8): 903-909 https://doi.org/10.1080/07373930903017376

Zade P P \& Lakade S S (2017). Optimization of process parameters for microwave-convective drying of grapes using response surface method. In: International Conference on Advances in Thermal Systems, Materials and Design Engineering, 21-22 December, Mumbai pp. 1-6 http://dx.doi.org/10.2139/ssrn.3101687

Zhang P, Zhou L, Bi J, Liu X, Lyu J, Chen Q \& Wu X (2017). Drying kinetics and quality attributes of peach cylinders as affected by osmotic pretreatments and infrared radiation drying. International Journal of Food Engineering 13(5): 1-10 https://doi.org/10.1515/ijfe-2016-0023

Zhu A \& Shen X (2014). The model and mass transfer characteristics of convection drying of peach slices. International Journal of Heat and Mass Transfer 72: 345-351 https://doi.org/10.1016/j.ijheatmasstransfer.2014.01.001

(C) 2021 by the authors. Licensee Ankara University, Faculty of Agriculture, Ankara, Turkey. This article is an open access article distributed under the terms and conditions of the Creative Commons Attribution (CC BY) license (http://creativecommons.org/licenses/by/4.0/). 